\title{
Sex addiction in Turkey: A large-scale survey with a national community sample
}

\author{
Kagan Kircaburun $^{1,2}$ (D) • Hüseyin Ünübol ${ }^{3} \cdot$ Gökben H. Sayar $^{4}$ • Jaklin Çarkçı ${ }^{3}$ - Mark D. Griffiths ${ }^{1}$
}

Accepted: 12 March 2021 / Published online: 25 March 2021

(C) The Author(s) 2021

\begin{abstract}
Prior studies on sex addiction have mostly relied on a narrow range of risk factors among small and heterogeneous samples. The purpose of the present study was to examine the psychological markers related to sex addiction in a large-scale community sample of Turkish adults. A total of 24,380 individuals completed a survey comprising the Sex Addiction Risk Questionnaire, the Brief Symptom Inventory, the Positive and Negative Affect Schedule, the Personal-Wellbeing Index Adult Form, the Toronto Alexithymia Scale, and the Experiences in Close Relationships-Revised ( $50 \%$ males; mean age $=31.79$ years; age range $=18$ to 81 years). Utilizing hierarchical regression analysis, sex addiction was associated with being male, being younger, having a lower education level, being single, being an alcohol and nicotine user, psychiatric distress, low personal wellbeing, positive and negative affect, alexithymia, and anxious attachment. This study suggests that socio-demographic factors and aforementioned detrimental psychological factors exacerbate higher engagement in addictive sexual behaviors among the Turkish community. However, more studies are needed to better understand the factors associated with sex addiction in Turkey.
\end{abstract}

Keywords Sex addiction $\cdot$ Psychiatric symptoms $\cdot$ Wellbeing $\cdot$ Affect $\cdot$ Alexithymia $\cdot$ Attachment

\section{Introduction}

The World Health Organization (2018) included compulsive sexual behavior disorder as an impulse-control disorder

Kagan Kircaburun

kircaburunkagan@gmail.com

Hüseyin Ünübol

huseyin.unubol@uskudar.edu.tr

Gökben H. Sayar

gokben.hizlisayar@uskudar.edu.tr

Jaklin Çarkçı

jaklin.carkci@uskudar.edu.tr

Mark D. Griffiths

mark.griffiths@ntu.ac.uk

1 International Gaming Research Unit, Psychology Department, Nottingham Trent University, 50 Shakespeare Street, Nottingham NG1 4FQ, UK

2 Educational Sciences Department, Düzce University, Düzce, Turkey

3 Institute of Social Sciences, Psychology Department, Üsküdar University, Istanbul, Turkey

4 Institute of Social Sciences, Clinical Psychology Department, Üsküdar University, Istanbul, Turkey in the eleventh revision of the International Classification of Diseases (ICD-11), and defined it as "a persistent pattern of failure to control intense, repetitive sexual impulses or urges resulting in repetitive sexual behavior." The conceptualization of this problematic behavior has received much debate among scholars and has led to the use of different terms to describe individuals' inability to control their sexual behaviors including (among others) sexual dependency, hypersexual disorder, sex addiction, and compulsive sexual behavior (Kafka, 2013; Karila et al., 2014). A recent study defined sex addiction as "being intensely involved with sexual activities (e.g., fantasies, masturbation, intercourse, pornography) across different media" (Andreassen et al., 2018; p.2). Furthermore, uncontrollable sexual drive, preoccupation with sex, and persistent engagement in sexual activities despite negative life consequences are among other symptoms reported for sex addiction (Andreassen et al., 2018). Despite the ongoing debate in labelling problematic sexual behavior as an obsessive-compulsive disorder, impulse-control disorder, or an addiction (Karila et al., 2014), recent research indicates that sex has the potential to be an addictive behavior and that sex addiction has different negative consequences including increased psychological and relationship distress (Griffiths, 2012; Reid et al., 2010; Spenhoff et al., 2013). 
In the past two decades, research into sex addiction has markedly increased. However, studies investigating the prevalence, risk factors, and consequences of sex addiction have relied on many different measurement tools to assess sex addiction including Sexual Addiction Screening Test-Revised (Carnes et al., 2010), Compulsive Sexual Behavior Inventory (Coleman et al., 2001), Sexual Dependency Inventory-Revised (Delmonico et al., 1998), and Sexual Symptom Assessment Scale (Raymond et al., 2007). However, many of the developed measures have important limitations including the specific and small samples used in development and validation studies, assessing specific sexual behaviors instead of sex addiction, having many items in the scale, and including inappropriate items in terms of the conceptualization of sex addiction (Andreassen et al., 2018; Hook et al., 2010). A recent study developed and validated the sixitem Bergen-Yale Sex Addiction Scale (BYSAS) with 23,533 Norwegian adults based on the components (i.e. salience, withdrawal, mood modification, conflict, tolerance, relapse) outlined in the biopsychosocial model (Andreassen et al., 2018; Griffiths, 2012).

More recently, Böthe et al. (2020) developed the Compulsive Sexual Behavior Disorder Scale (CSBD-19) based on the ICD-11 screening measure comprising 9325 individuals from United States, Hungary, and Germany. The five-factor model of the CSBD-19 (i.e. control, salience, relapse, dissatisfaction, negative consequences) demonstrated positive associations with hypersexual behavior, problematic pornography consumption, number of sexual partners, number of casual sexual partners, past-year frequency of having sex with the partner, past-year frequency of having sex with casual partners, past-year frequency of masturbation, and pastyear frequency of pornography viewing (Böthe et al., 2020).

Others have tested the psychometric properties of the Hypersexual Behavior Inventory (HBI) using a large-scale nonclinical sample comprising 18,034 individuals from Hungary (Bőthe, Kovács, et al., 2019a). The three-factor model of the HBI (i.e. coping, control, consequences) had positive relationships with number of sexual partners, number of casual sexual partners, frequency of having sex with the partner, frequency of having sex with casual partners, frequency of masturbation, frequency of pornography viewing per occasion, and frequency of pornography viewing.

The extant sex addiction literature indicates conflicting findings in terms of sex addiction's socio-demographic determinants. In a recent study, men were better characterized with having higher levels of sexual fantasies, masturbation frequency, ease of sexual arousal, and casual sex when compared to women, although more research that focus on women are needed to establish the role of gender in the development of sex addiction (Böthe et al., 2018, 2020). Nevertheless, existing evidence suggests a male dominance in addictive sexual behavior (Kafka, 2010), although some studies have shown that females may also be susceptible to engage in addictive sexual behaviors and this can lead to elevated feelings of shame (Dhuffar \& Griffiths, 2014, 2015). In terms of age, studies suggest that adolescence and young adulthood are the riskiest periods for developing and maintaining sex addiction (Kafka, 2010). In a Norwegian large-scale study of over 23,500 participants, having a Master's degree lowered the odds of having moderate sex addiction risk whereas having a PhD degree elevated the risk of having sex addiction (Andreassen et al., 2018). Consequently, being male, lower age, being single, high education level, alcohol use, and tobacco use have been related to elevated hypersexuality and sex addiction (Andreassen et al., 2018; Campbell \& Stein, 2015; Kafka, 2010; Sussman et al., 2011).

In addition to socio-demographic factors, previous studies have identified several psychological correlates of sex addiction. A study with 418 male sex addicts showed that the prevalence rate of depression was much higher among American sex addicts when compared to general population (Weiss, 2004). Individuals with sex addiction had elevated psychiatric distress and impairment due to experiencing difficulty controlling sexual feelings, urges, and behavior (Dickenson et al., 2018). It appears that those with increased stress and anxiety levels attempt to cope with their negative mental states by engaging in addictive sexual behaviors (Brewer \& Tidy, 2019). Among 337 emerging adults, sex addiction was associated with regulating negative affect and relieving affective distress (Cashwell et al., 2017). It has also been empirically shown that negative mood states are associated with elevated hypersexuality among emerging adults (Dhuffar et al., 2015). Furthermore, difficulty identifying feelings was positively related to elevated sex addiction after controlling for depression and vulnerability to stress (Reid et al., 2008), indicating that alexithymic individuals are also at risk of sex addiction. Furthermore, sexually addicted individuals have been found to have more insecure (i.e., anxious, avoidant) attachment styles (Zapf et al., 2008). Nevertheless, given that addictive sexual behaviors are impulsive and compulsive in nature, psychological problems can be expected to correlate with sex addiction (Böthe, Tóth-Király, et al., 2019b). Moreover, those who attempt or complete suicide are characterized by mood disorders, stressful life events, interpersonal problems, poor social support, lonely lives, alexithymia, and feelings of hopelessness due to temperamental traits or maladaptive attachments styles (Pompili et al., 2014). Importantly, the unique sensory processing patterns of depressed individuals have been reported as crucial factors in determining unfavorable outcomes (Serafini et al., 2017). Consequently, examining these overlapping constructs that have been repeatedly shown to predict sex addiction in previous studies was considered to be beneficial for understanding sex addiction among Turkish individuals. 
Despite the extant literature, there is very little empirically known regarding sex addiction in Turkey. Therefore, the present study used a large Turkish sample to examine specific psychological determinants of sex addiction that have been consistently identified as risk factors for addictive sexual behaviors and other behavioral addictions in the extant literature including psychiatric symptoms, personal wellbeing, affective states, alexithymia, and attachment. In this context, firstly, the relationship between demographic variables such as gender, age, education level, marital status, cigarette smoking, alcohol use and sex addiction was examined. In addition to these, it was aimed to determine the predictive power of psychiatric symptoms, personal wellbeing, affective states, alexithymia, and attachment variables together on sex addiction. Only a few studies have addressed these issues, and the existing studies suffer from several limitations including self-selected small samples, and non-representative and heterogenous populations. These limitations diminish the reliability and definitiveness of the prior studies' results.

The present study validated and utilized a newly developed scale, the Sex Addiction Risk Questionnaire (SARQ). The SARQ was developed because the present study was a large-scale epidemiological study examining a wide range of addictive behaviors in which the items were identical but participants were asked to respond to them in relation to specific behaviors (e.g., food, gaming, etc.). The present study only reports the findings in relation to sex addiction. It was hypothesized that being male, being younger, high education level, cigarette smoking, alcohol use, psychiatric distress, poor personal well-being, affective states, alexithymia, and insecure attachment styles would all be positively correlated with sex addiction.

\section{Methods}

\section{Participants and Procedure}

The primary objective of the sampling was an attempt to represent the adult population in Turkey. To do this, it was ensured that the sample reference frame was created and the participants from specific strata in Turkish society were included in the study framework. NUTS (nomenclature of territorial units for statistics) classification, which is a system used to divide up the economic territory of the European Union, was used to plan the sampling. With this classification system, adult population representativeness is increased. The sampling approach aimed to survey a specific number of participants from each specified strata within specific territorial regions covering the whole of Turkey. Depending on the population of the cities, data between 200 and 2000 were collected from each territory so that the sample could be as representative as possible. A total of 125 psychology graduate students administered the paper-and-pencil questionnaires to individuals from 79 different cities in 26 regions of Turkey in 2018. The research team recruited participants from different communities and ensured that participants were alone and comfortable while answering sensitive questions (i.e., questions concerning sexual behavior). Those who were over 18 years of age, and did not have a mental illness that prevents them from completing the questionnaires recruited for the study. A total of 24,494 Turkish adults filled out the questionnaires. When the data were examined, it was found that some participants did not complete all the questions, and some participants did not respond to some of the scales. Of these, participants who had missing data and/or who did not respond to more than one scale were classed as having too many missing data. Missing data are known constitute threats to different forms of reliability, validity, and generalizability of study results. These missing data were excluded from the analyses in order to prevent bias. However, given the very large sample size, this did not reduce the statistical power of the study, or the representativeness of the sample. The final sample consisted 24,380 participants (12,249 men and 12,131 women; $M_{\text {age }}=31.79$ years, $S D_{\text {age }}=10.86$; range $=18$ to 81 years). Data used in this study were collected as part of a much bigger epidemiological study examining multiple addictive behaviors, some of which have been published elsewhere (i.e., Kircaburun et al., 2020; Ünübol et al., 2020).

\section{Measures}

Demographic Variables Sociodemographic information form included gender, age, education status, marital status, cigarette use, and alcohol use.

Sex Addiction Risk Questionnaire (SARQ) Sex addiction was assessed using the unidimensional SARQ (see Appendix). The scale comprises six items that assess six addiction criteria outlined based on the 'addiction components model' (Griffiths, 2012). Participants rated SARQ items using a 11-point scale ranging from 0 (never) to 10 (always). The Cronbach's $\alpha$ in the present study was excellent (.93).

Brief Symptom Inventory (BSI) General psychiatric distress was assessed using the Turkish form (Sahin \& Durak, 1994) of the 53-item BSI (Derogatis \& Spencer, 1993). The scale has five sub-dimensions comprising negative self-concept, depression, anxiety, somatization, and hostility. Participants rate the BSI items using a five-point scale ranging from 1 (almost never) to 5 (almost always). The scale was used to assess general psychiatric distress by using the scale as a single construct, The Cronbach's $\alpha$ in the present study was excellent (.95). 
Personal Well-Being Index Adult Form (PWBI-AF) General well-being of the participants was assessed using the Turkish form (Meral, 2014) of eight-item PWBI-AF (International Wellbeing Group, 2013). Participants rated the PWBI-AF items using an 11-point scale ranging from 0 (No satisfaction at all) to 10 (Completely satisfied). The Cronbach's $\alpha$ in the present study was very good (.87).

Positive and Negative Affect Schedule (PANAS) Positive and negative affect at a given point in time were assessed using the Turkish form (Gençöz, 2000) of the 20-item PANAS (Watson et al., 1988). Participants rated the PANAS items using a fivepoint Likert scale ranging from 1 (very slightly) to 5 (extremely). Higher scores indicate having more positive affect (Cronbach's $\alpha=.85$ ) and negative affect (Cronbach's $\alpha=.83)$.

Toronto Alexithymia Scale (TAS-20) Alexithymia and its subdimensions including difficulty identifying feelings, difficulty describing feelings, and externally-oriented thinking were assessed using the Turkish form (Güleç et al., 2009) of the 20-item TAS-20 (Bagby et al., 1994). Because of the recent arguments on whether externally-oriented thinking (EOT) represents alexithymia (Müller et al., 2003) EOT was excluded from the analyses. Participants rated the TAS-20 using a five-point scale ranging from 1 (strongly disagree) to 5 (strongly agree). The Cronbach's $\alpha$ in the present study was very good (.83).

Experiences in Close Relationships-Revised (ECR-R) Anxious and avoidant attachment were assessed using the Turkish form (Selçuk et al., 2005) of 36-item ECR-R (Fraley et al., 2000). Participants rated ECR-R items using a seven-point scale ranging from 1 (strongly disagree) to 7 (strongly agree). Higher scores indicate more anxious attachment (Cronbach's $\alpha=.83$ ) and avoidant attachment (Cronbach's $\alpha=.85$ ).

\section{Statistical Analysis}

The data-analytic strategy addressed the following steps: (i) psychometric validation of the SARQ; and (ii) investigation of socio-demographic and psychological correlates of sex addiction. Initially, psychometric properties of SARQ were evaluated using classical test theory (CTT), exploratory factor analysis (EFA), and confirmatory factor analysis (CFA). In CFA, root mean square residuals (RMSEA), standardized root mean square residuals (SRMR), comparative fit index (CFI), and goodness of fit index (GFI) were checked to determine goodness of fit. RMSEA and SRMR lower than .05 indicate good fit and RMSEA and SRMR lower than .08 suggest adequate fit; CFI and GFI higher than .95 is good and CFI and GFI higher than .90 is acceptable (Hu \& Bentler, 1999).

In the final step, Pearson's correlation tests were utilized to explore correlation coefficients among study variables and hierarchical regression analyses were utilized to predict sex addiction based on socio-demographical factors and psychological variables. Before the correlation analysis, data met the assumption of normality based on the skewness and kurtosis values. In the regression analysis, it was confirmed that there were no multicollinearity via examining variance inflation factor (VIF) and tolerance values. Statistical analyses were carried out using SPSS 23.0 and AMOS 23.0 software.

\section{Results}

The total sample was randomly divided into two separate samples in order to carry out EFA and CFA using two samples. EFA was carried out with the first sample $(N=12,096)$. EFA indicated that the SARQ had a unidimensional factor structure. The Kaiser-Meyer-Olkin measure and Barlett's test of sphericity $(.89 ; p<.001)$ in EFA suggested a one-factor solution. Principal component analysis indicated all items had high loads (communalities ranging between .62 and .81), explaining $73.32 \%$ of the total variance. The one-factor solution was based on the scree plot in which the factors that had an Eigenvalue higher than 1 were extracted. A CFA was performed following the EFA using the second sample $(N=12,284)$. Maximum likelihood discrepancy estimation method was used in the CFA. The observed indicator variables (i.e., items of the scale) of the latent variables were specified as continuous indicators. Goodness of fit indices $\left(\chi^{2}=2497.97, \mathrm{df}=6, p<.001\right.$, RMSEA $=.13$ CI $90 \%[.13, .13]$, SRMR $=.03, \mathrm{CFI}=.98$, GFI $=.97)$ indicated mostly good fit to the data (Kline, 2011), confirming the fit adequacy of the one-factor solution. According to the standardized factor loadings (ranging between .72 and .90), all items had a significant role in the scale.

Table 1 demonstrates mean scores, standard deviations, and correlation coefficients of the study variables. Sex addiction was positively correlated with psychiatric distress $(\mathrm{r}=.17, p<.001)$, alexithymia $(\mathrm{r}=.13, p<.001)$, positive affect $(\mathrm{r}=.06, p<.001)$, negative affect $(\mathrm{r}=.14, p<.001)$, and anxious attachment $(\mathrm{r}=.10, p<.001)$. Additionally, sex addiction was negatively correlated with personal wellbeing $(\mathrm{r}=-.10, p<.001)$ whereas it did not correlate with avoidant attachment $(\mathrm{r}=.00, p>.05)$. Given the low correlation coefficient $(\mathrm{r}<.10)$, the correlation of positive affect $(\mathrm{r}=.06, p<.001)$ with sex addiction most likely achieved statistical significance due to the large sample size.

Table 2 shows the results of hierarchical regression analysis. Sex addiction was positively associated with being male ( $\beta=-.31, p<.001)$, being single $(\beta=-.03, p<.001)$, 
Table 1 Mean scores, standard deviations, and Pearson's correlations coefficients of the study variables

\begin{tabular}{lllllllll}
\hline & 1 & 2 & 3 & 4 & 5 & 6 & 7 & 8 \\
\hline 1. Sex addiction & - & & & & & & \\
2. Psychiatric distress & $.17^{*}$ & - & & & & & & \\
3. Alexithymia & $.13^{*}$ & $.65^{*}$ & - & & & & \\
4. Positive affect & $.06^{*}$ & $-.15^{*}$ & $-.10^{*}$ & - & & & & \\
5. Negative affect & $.14^{*}$ & $.58^{*}$ & $.46^{*}$ & $-.10^{*}$ & - & & & \\
6. Personal wellbeing & $-.10^{*}$ & $-.44^{*}$ & $-.31^{*}$ & $.38^{*}$ & $-.35^{*}$ & - & & \\
7. Avoidant attachment & .00 & $.24^{*}$ & $.20^{*}$ & $-.28^{*}$ & $.23^{*}$ & $-.29 *$ & - & \\
8. Anxious attachment & $.10^{*}$ & $.44^{*}$ & $.41^{*}$ & $-.10^{*}$ & $.37^{*}$ & $-.20^{*}$ & $.21 *$ & - \\
\multicolumn{1}{c}{$M$} & 7.66 & 98.20 & 26.78 & 30.42 & 19.46 & 51.45 & 60.27 & 60.21 \\
\multicolumn{1}{c}{$S D$} & 12.35 & 29.04 & 7.61 & 7.97 & 6.83 & 15.95 & 19.23 & 18.36 \\
\hline
\end{tabular}

$* p<.001$

cigarette smoking $(\beta=-.04, p<.01)$, alcohol use $(\beta=-.16$, $p<.01)$, psychiatric distress $(\beta=.13, p<.05)$, positive affect $(\beta=.06, p<.001)$, negative affect $(\beta=.03, p<.01)$, alexithymia $(\beta=.02, p<.001)$, and anxious attachment $(\beta=.04, p<.001)$. Sex addiction was negatively associated with age $(\beta=-.04, p<.001)$, education $(\beta=-.02, p<.001)$, personal well-being $(\beta=-.02, p<.01)$, and avoidant attachment $(\beta=-.02, p<.01)$. However, it should be noted that the predictive effects of age, education, marital status, cigarette smoking, personal well-being, negative affect, and attachment styles were all very small. Furthermore, these effects might have become statistically significant due to the large sample size. The regression model predicted $18 \%$ of the variance in sex addiction $\left(\mathrm{F}_{13,24,161}=418.62, p<.001\right)$.
Table 2 Hierarchical regression analysis predicting sex addiction

\begin{tabular}{|c|c|c|c|c|c|}
\hline Model & $\mathrm{B}$ & $\mathrm{SE}$ & $\beta$ & $t$ & $\Delta \mathrm{R}^{2}$ \\
\hline \multicolumn{5}{|c|}{ Block $1\left(\mathrm{R}_{\text {Adjusted }}^{2}=.15 ; F_{(6,24,168)}=718.52 ; p<.001\right)$} & .15 \\
\hline Gender $^{\mathrm{a}}$ & -7.67 & .15 & -.30 & $-49.28 * *$ & \\
\hline Age & -.08 & .01 & -.07 & $-9.75 * *$ & \\
\hline Education $^{\mathrm{b}}$ & -.59 & .08 & -.05 & $-7.49 * *$ & \\
\hline Marital Status ${ }^{\mathrm{c}}$ & -.30 & .15 & -.01 & -2.34 & \\
\hline Cigarette smoking $^{\mathrm{d}}$ & -1.39 & .13 & -.06 & $-9.82 * *$ & \\
\hline Alcohol use $^{\mathrm{d}}$ & -4.25 & .14 & -.17 & $-27.58 * *$ & \\
\hline \multicolumn{5}{|c|}{ Block $2\left(\mathrm{R}^{2}{ }_{\text {Adjusted }}=.18 ; F_{(13,24,161)}=418.62 ; p<.001\right)$} & .03 \\
\hline Gender $^{\mathrm{a}}$ & -7.59 & .15 & -.31 & $-51.17^{* *}$ & \\
\hline Age & -.04 & .01 & -.04 & $-5.45 * *$ & \\
\hline Education $^{\mathrm{b}}$ & -.35 & .08 & -.03 & $-4.30 * *$ & \\
\hline Marital Status ${ }^{\mathrm{c}}$ & -.65 & .15 & -.03 & $-4.39 * *$ & \\
\hline Cigarette smoking ${ }^{\mathrm{d}}$ & -.87 & .13 & -.04 & $-6.82 * *$ & \\
\hline Alcohol use ${ }^{\mathrm{d}}$ & -4.10 & .16 & -.16 & $-25.23 * *$ & \\
\hline Psychiatric distress & .06 & .00 & .13 & $14.37 * *$ & \\
\hline Personal well-being & -.02 & .01 & -.02 & $-3.01 *$ & \\
\hline Positive affect & .09 & .01 & .06 & $9.28 * *$ & \\
\hline Negative affect & .05 & .01 & .03 & $3.92 *$ & \\
\hline Alexithymia & .03 & .01 & .02 & $2.02 * *$ & \\
\hline Avoidant attachment & -.26 & .07 & -.02 & $-3.49^{*}$ & \\
\hline Anxious attachment & .49 & .08 & .04 & $6.06 * *$ & \\
\hline
\end{tabular}

Note. $\mathrm{B}=$ unstandardized regression coefficient; $\mathrm{SE}=$ Standard error; $\beta=$ standardized regression coefficient; ${ }^{\mathrm{a}}$ Male $=1$, Female $=2 ;{ }^{\mathrm{b}}$ Primary school $=1$, Secondary school $=2$, High school $=3$, Bachelor $=4$, Post-graduate $=5 ;{ }^{\mathrm{c}}$ Single $=1$, Married $=2 ;{ }^{\mathrm{d}}$ Yes $=1, \mathrm{No}=2 ; * p<.01, * * p<.001$ 


\section{Discussion}

The findings of the present study showed that being male, being younger, having a lower education level, being single, cigarette smoking, alcohol use, psychiatric distress, positive and negative affect, alexithymia, anxious attachment, lower personal well-being, and lower avoidant attachment were all positively associated with sex addiction. Therefore, all the hypotheses were supported. As expected, psychiatric distress was positively associated with sex addiction. This is consistent with the previous studies that have shown that psychiatric symptoms including depression, anxiety, and stress can lead to elevated engagement in addictive sexual behaviors (Brewer \& Tidy, 2019; Weiss, 2004). It may be that these aforementioned detrimental psychological states lead to decreased behavioral control among such individuals (Dickenson et al., 2018). Individuals try and distract themselves using excessive sexual engagement to fill an emotional void that is caused by negative emotions such as depression, anxiety, and stress (Young, 2008).

Both positive and negative affect were positively related to sex addiction. This is in line with the existing studies suggesting that sex addiction is associated with affective mental states (Cashwell et al., 2017). One possible explanation may be that those individuals who struggle with frequent negative affective states and emotional turbulence use preoccupation with sexual behaviors as a mood modification mechanism in which they have pleasurable feelings that help them avoid negative feelings (Woehler et al., 2018). It is also important to note that affective mental states were significant even after controlling for psychiatric distress, emphasizing the unique exacerbating role of negative affect. However, it should also be noted that positive affect was also positively related to sex addiction. This is somewhat unexpected, given the existing empirical evidence suggesting that positive mood is a protective factor in reducing behavioral addictions (Cardi et al., 2019). Nevertheless, the result is in line with the notion that affective triggers may vary in addictive behaviors (Messer et al., 2018) and both negative and positive emotions could lead to elevated engagement in addictive sexual behaviors.

The study also found that higher alexithymia (e.g., difficulty identifying and expressing feelings) was positively correlated with sex addiction. Those who experienced difficulties in identifying and expressing their feelings were at more risk for becoming sex addicts. This is consistent with the small extant literature examining the relationship between these two variables (Reid et al., 2008). One of the few studies examining the relationship found that increased alexithymia was prevalent among males with hypersexual disorder (Engel et al., 2019). It was argued that dysfunctional emotion regulation abilities of individuals with elevated alexithymia could be the underlying problem that lead these individuals to more sex addiction.

Results also showed that anxious attachment was positively associated with sex addiction. This is in line with the previous studies positing that insecure attachment is positively related to sex addiction (Zapf et al., 2008). Those who experience difficulties in forming secure attachment with others are susceptible to have problems in intimate relationships (Schwartz \& Southern, 1999). Anxiously attached individuals may use excessive, compulsive, and unrealistic sexual fantasies as a compensation for their lack of intimacy and emotional interaction (Leedes, 2001). Consequently, anxiously attached individuals may engage in excessive sex without emotional commitment in order to ease their fear of separation and abandonment (Weinstein et al., 2015). The association between avoidant attachment and sex addiction was nonsignificant in the correlation analysis but it was negatively significant in the regression. Consequently, it may be that a suppressor variable (e.g., psychiatric distress) affected this association.

As expected, socio-demographic factors appeared to play a role in sex addiction in the present study. More specifically, being male, being younger, having a lower education level, being single, cigarette smoking, and alcohol use were related to sex addiction. These aforementioned associations are consistent with the findings of previous studies in different countries (Andreassen et al., 2018; Campbell \& Stein, 2015; Kafka, 2010; Sussman et al., 2011). The findings suggest that socio-demographic features should be taken into account when developing targeted intervention strategies for preventing sex addiction.

\section{Limitations}

The findings of the present study should be interpreted while taking a number of limitations into account. First, despite the fact that the sample was very large and data collection was made to obtain a homogenious group, this study does not nationally represent Turkish community. The present findings should be replicated using more representative samples from Turkey and/or other developing countries where sex addiction has been less examined. Second, any causality on the associations examined among the study variables cannot be determined due to the cross-sectional design of this study. Longitudinal and qualitative methods should be used to have more in-depth studies in order to further examine the present findings. Third, self-report questionnares with well-known methodological biases (e.g., memory recall and social desirability) were used to collect the data. Fourth, given that data were self-reported and collected at one time point, the relationships between study variables may have been inflated. 


\section{Conclusion}

Despite the aforementioned limitations, this is the first largescale examination investigating the psychological correlates of sex addiction among a Turkish community sample. The psychometric properties of a newly developed scale assessing sex addiction (i.e., Sex Addiction Risk Questionnaire) were tested combining CTT, EFA, and CFA. Furthermore, the socio-demographic and psychological correlates of sex addiction were examined. The most important conclusion that can be drawn from this study is that psychiatric symptoms, poor personal well-being, affective states, alexithymia, and anxious attachment were the primary psychological correlates of sex addiction while controlling for socio-demographic factors. The present results suggest that in order to have a clearer understanding of sex addiction, it is important to collect data on a wide range of variables. It would be beneficial to investigate mediating and moderating effects of psychological variables in future studies to better explain the underlying mechanisms of sex addiction. The moderating effect of sociodemographic variables such as gender, education level, alcohol use, and cigarette smoking, which were found to be associated with sex addiction in the present study, can be further determined. Mediating models between the variables discussed in the study or new variables (e.g., psychopathological problems, ruminative thoughts, psychotrauma-related problems, individual difference factors) and sex addiction can be investigated. Only in this way will it be possible to know the various direct and indirect effects on sex addiction, providing greater insight concerning the underlying mechanisms that may correlate with sex addiction. Even though this study provides valuable contribution, further studies are warranted in order to develop effective prevention and intervention strategies for sex addiction.

\section{Appendix}

\section{Please rate below items considering your sexual behavior}

1. This behavior has become the centre of my life, often comes to my mind, and I often engage in it. Even if I'm not doing it, I'm thinking about when I can. I get some relief when I plan to engage in the behavior. Sometimes there is an urge that is so powerful, I find a way to engage in the behavior, and I cannot prevent it. (Salience)

2. Sometimes, when I'm bored, sometimes when I'm happy, I think of this behavior and I do it. Many times when my problems increase, my urge to engage in the behavior increases. If I'm unable to do it, my mind doesn't relax. It's like I'm alive. (Mood modification)
3. Even if I engage in the behavior at the same rate, sometimes it's not enough for me, I have to engage in it more. I have to increase the time and amount I engage in the behavior or I won't relax. (Tolerance)

4. When I'm in a place where it's impossible for me to engage in the behavior, or when I try to stop myself, or when someone sees my problem and tries to interfere, I feel symptoms of tension psychologically or physically. (Withdrawal)

5. Engaging in the behavior causes me to have problems in my environment, my social life is badly affected, it can disrupt my work, and I often get criticized about it. (Conflict)

6. If I do stop engaging in the behavior, it can be triggered again and I when it does it's like it never stopped in the first place. (Relapse)

Data Availability The datasets generated during and/or analysed during the current study are available from the corresponding author on reasonable request.

\section{Declarations}

Ethical Statement Ethical approval for the study was obtained from the research team's university ethical committee board.

Informed Consent All participants gave their informed consent prior to participating in the study.

Conflict of Interest There is no conflict of interest.

Open Access This article is licensed under a Creative Commons Attribution 4.0 International License, which permits use, sharing, adaptation, distribution and reproduction in any medium or format, as long as you give appropriate credit to the original author(s) and the source, provide a link to the Creative Commons licence, and indicate if changes were made. The images or other third party material in this article are included in the article's Creative Commons licence, unless indicated otherwise in a credit line to the material. If material is not included in the article's Creative Commons licence and your intended use is not permitted by statutory regulation or exceeds the permitted use, you will need to obtain permission directly from the copyright holder. To view a copy of this licence, visit http://creativecommons.org/licenses/by/4.0/.

\section{References}

Andreassen, C. S., Pallesen, S., Griffiths, M. D., Torsheim, T., \& Sinha, R. (2018). The development and validation of the Bergen-Yale Sex Addiction Scale with a large national sample. Frontiers in Psychology, 9, 144.

Bagby, R. M., Taylor, G. J., \& Parker, J. D. (1994). The twenty-item Toronto Alexithymia Scale-II. Convergent, discriminant, and concurrent validity. Journal of Psychosomatic Research, 38, 33-40.

Böthe, B., Bartók, R., Tóth-Király, I., Reid, R. C., Griffiths, M. D., Demetrovics, Z., \& Orosz, G. (2018). Hypersexuality, gender, and sexual orientation: A large-scale psychometric survey study. Archives of Sexual Behavior, 47, 2265-2276. 
Bőthe, B., Kovács, M., Tóth-Király, I., Reid, R. C., Griffiths, M. D., Orosz, G., \& Demetrovics, Z. (2019a). The psychometric properties of the Hypersexual Behavior Inventory using a large-scale nonclinical sample. Journal of Sex Research, 56(2), 180-190.

Bőthe, B., Tóth-Király, I., Potenza, M. N., Griffiths, M. D., Orosz, G., \& Demetrovics, Z. (2019b). Revisiting the role of impulsivity and compulsivity in problematic sexual behaviors. Journal of Sex Research, 56, 166-179.

Bőthe, B., Potenza, M. N., Griffiths, M. D., Kraus, S. W., Klein, V., Fuss, J., \& Demetrovics, Z. (2020). The development of the Compulsive Sexual Behavior Disorder Scale (CSBD-19): An ICD-11 based screening measure across three languages. Journal of Behavioral Addictions, 9, 247-258.

Brewer, G., \& Tidy, P. (2019). Sex addiction: Therapist perspectives. Sexual and Relationship Therapy, 34, 40-53.

Campbell, M. M., \& Stein, D. J. (2015). Hypersexual disorder. In N. M. Petry (Ed.), Behavioral addictions: DSM-5® and beyond (pp. 101123). Bantam Books.

Cardi, V., Leppanen, J., Leslie, M., Esposito, M., \& Treasure, J. (2019). The use of a positive mood induction video-clip to target eating behaviour in people with bulimia nervosa or binge eating disorder: An experimental study. Appetite, 133, 400-404.

Carnes, P., Green, B., \& Carnes, S. (2010). The same yet different: Refocusing the Sexual Addiction Screening Test (SAST) to reflect orientation and gender. Sexual Addiction \& Compulsivity, 17(1), 7-30.

Cashwell, C. S., Giordano, A. L., King, K., Lankford, C., \& Henson, R. K. (2017). Emotion regulation and sex addiction among college students. International Journal of Mental Health and Addiction, $15,16-27$.

Coleman, M. M., Ohlerking, F., \& Nancy Raymond, E. (2001). Compulsive Sexual Behavior Inventory: A preliminary study of reliability and validity. Journal of Sex \& Marital Therapy, 27, 325-332.

Delmonico, D. L., Bubenzer, D. L., \& West, J. D. (1998). Assessing sexual addiction with the Sexual Dependency Inventory-Revised. Sexual Addiction \& Compulsivity, 5, 179-187.

Derogatis, L. R., \& Spencer, P. M. (1993). Brief Symptom Inventory: BSI. Pearson.

Dhuffar, M., \& Griffiths, M. (2014). Understanding the role of shame and its consequences in female hypersexual behaviours: A pilot study. Journal of Behavioral Addictions, 3, 231-237.

Dhuffar, M. K., \& Griffiths, M. D. (2015). Understanding conceptualisations of female sex addiction and recovery using interpretative phenomenological analysis. Psychology Research, 5, 585603

Dhuffar, M. K., Pontes, H. M., \& Griffiths, M. D. (2015). The role of negative mood states and consequences of hypersexual behaviours in predicting hypersexuality among university students. Journal of Behavioral Addictions, 4, 181-188.

Dickenson, J. A., Gleason, N., Coleman, E., \& Miner, M. H. (2018). Prevalence of distress associated with difficulty controlling sexual urges, feelings, and behaviors in the United States. JAMA Network Open, 1, e184468.

Engel, J., Veit, M., Sinke, C., Heitland, I., Kneer, J., Hillemacher, T., ... \& Kruger, T. H. (2019). Same same but different: A clinical characterization of men with hypersexual disorder in the sex@ brain study. Journal of Clinical Medicine, 8, e157.

Fraley, R. C., Waller, N. G., \& Brennan, K. A. (2000). An item response theory analysis of self-report measures of adult attachment. Journal of Personality and Social Psychology, 78, 350-364.

Gençöz, T. (2000). Positive and Negative Affect Schedule: A study of validity and reliability. Turk Psikoloji Dergisi, 15, 19-26.

Griffiths, M. D. (2012). Internet sex addiction: A review of empirical research. Addiction Research \& Theory, 20, 111-124.

Gülec, H., Köse, S., Gülec, M. Y., Citak, S., Evren, C., Borckardt, J., \& Sayar, K. (2009). Reliability and factorial validity of the Turkish version of the 20-item Toronto Alexithymia Scale (TAS-20). Klinik Psikofarmakoloji Bulteni, 19, 214-220.

Hook, J. N., Hook, J. P., Davis, D. E., Worthington Jr., E. L., \& Penberthy, J. K. (2010). Measuring sexual addiction and compulsivity: A critical review of instruments. Journal of Sex \& Marital Therapy, 36, 227-260.

$\mathrm{Hu}, \mathrm{L} . \mathrm{T}$., \& Bentler, P. M. (1999). Cutoff criteria for fit indexes in covariance structural analysis: Conventional criteria versus new alternatives. Structural Equation Modelling, 6, 1-55.

International Wellbeing Group (2013). Personal Wellbeing Index-Adult. Australian Centre on Quality of Life, Deakin University, Retrieved December 8, 2020, from http://www.acqol.com.au/uploads/pwi-a/ pwi-a-english.pdf.

Kafka, M. P. (2010). Hypersexual disorder: A proposed diagnosis for DSM-V. Archives of Sexual Behavior, 39, 377-400.

Kafka, M. P. (2013). The development and evolution of the criteria for a newly proposed diagnosis for DSM-5: Hypersexual disorder. Sexual Addiction \& Compulsivity, 20, 19-26.

Karila, L., Wéry, A., Weinstein, A., Cottencin, O., Petit, A., Reynaud, M., \& Billieux, J. (2014). Sexual addiction or hypersexual disorder: Different terms for the same problem? A review of the literature. Current Pharmaceutical Design, 20, 4012-4020.

Kline, R. B. (2011). Principles and practices of structural equation modeling (2nd ed.). Guilford.

Kircaburun, K., Ünübol, H., Sayar, G. H., Stavropoulos, V. \& Griffiths, M. D. (2020). Psychological variables predicting problematic gaming among Turkish community: A largescale national study. International Journal of Mental Health and Addiction. Advance online publication. https://doi.org/10.1007/s11469-020-00254-8.

Leedes, R. (2001). The three most important criteria in diagnosing sexual addictions: Obsession, obsession, and obsession. Sexual Addiction \& Compulsivity, 8, 215-226.

Meral, B. F. (2014). Psychometric properties of Turkish form of the Personal Well-Being Index-Adult. Journal of Happiness and WellBeing, 2, 119-131.

Messer, S., Siegel, A., Bertin, L., \& Erblich, J. (2018). Sex differences in affect-triggered lapses during smoking cessation: A daily diary study. Addictive Behaviors, 87, 82-85.

Müller, J., Bühner, M., \& Ellgring, H. (2003). Is there a reliable factorial structure in the 20-item Toronto Alexithymia Scale?: A comparison of factor models in clinical and normal adult samples. Journal of Psychosomatic Research, 55, 561-568.

Pompili, M., Innamorati, M., Lamis, D. A., Erbuto, D., Venturini, P., Ricci, F., Serafini G., Amore M. \& Girardi, P. (2014). The associations among childhood maltreatment,"male depression" and suicide risk in psychiatric patients. Psychiatry Research, 220, 571-578.

Raymond, N. C., Lloyd, M. D., Miner, M. H., \& Kim, S. W. (2007). Preliminary report on the development and validation of the Sexual Symptom Assessment Scale. Sexual Addiction \& Compulsivity, 14, $119-129$

Reid, R. C., Carpenter, B. N., Spackman, M., \& Willes, D. L. (2008). Alexithymia, emotional instability, and vulnerability to stress proneness in patients seeking help for hypersexual behavior. Journal of Sex \& Marital Therapy, 34, 133-149.

Reid, R. C., Carpenter, B. N., Draper, E. D., \& Manning, J. C. (2010). Exploring psychopathology, personality traits, and marital distress among women married to hypersexual men. Journal of Couple \& Relationship Therapy, 9, 203-222.

Sahin, N. H., \& Durak, A. (1994). Kisa Semptom Envanteri (Brief Symptom Inventory-BSI): Turk Gencleri Icin Uyarlanmasi [A study of the Brief Symptom Inventory in Turkish youth]. Türk Psikoloji Dergisi, 9, 44-56.

Schwartz, M. F., \& Southern, S. (1999). Manifestations of damaged development of the human affectional systems and developmentally based psychotherapies. Sexual Addiction \& Compulsivity, 6, 163175 . 
Selçuk, E., Günaydın, G., Sümer, N., \& Uysal, A. (2005). A new scale developed to measure adult attachment dimensions: Experiences in Close Relationships-Revised (ECR-R) - Psychometric evaluation in a Turkish sample. Türk Psikoloji Yazılarl, 8, 1-11.

Serafini, G., Gonda, X., Canepa, G., Pompili, M., Rihmer, Z., Amore, M., \& Engel-Yeger, B. (2017). Extreme sensory processing patterns show a complex association with depression, and impulsivity, alexithymia, and hopelessness. Journal of Affective Disorders, 210, 249-257.

Spenhoff, M., Kruger, T. H., Hartmann, U., \& Kobs, J. (2013). Hypersexual behavior in an online sample of males: Associations with personal distress and functional impairment. Journal of Sexual Medicine, 10, 2996-3005.

Sussman, S., Lisha, N., \& Griffiths, M. (2011). Prevalence of the addictions: A problem of the majority or the minority? Evaluation \& the Health Professions, 34, 3-56.

Ünübol, H., Koç, A. S., Sayar, G. H., Kircaburun, K. \& Griffiths, M. D. (2020). Measurement, profiles, prevalence, and psychological risk factors associated with addictive food consumption: Evidence from a national largescale sample. Journal of Behavioral Addictions. Advance online publication. https://doi.org/10.1556/2006.2020. 00052.

Watson, D., Clark, L. A., \& Tellegen, A. (1988). Development and validation of brief measures of positive and negative affect: The
PANAS scales. Journal of Personality and Social Psychology, 54, 1063-1070.

Weinstein, A., Katz, L., Eberhardt, H., Cohen, K., \& Lejoyeux, M. (2015). Sexual compulsion - Relationship with sex, attachment and sexual orientation. Journal of Behavioral Addictions, 4, 22-26.

Weiss, D. (2004). The prevalence of depression in male sex addicts residing in the United States. Sexual Addiction \& Compulsivity, 11, 57-69.

Woehler, E. S., Giordano, A. L., \& Hagedorn, W. B. (2018). Moments of relational depth in sex addiction treatment. Sexual Addiction \& Compulsivity, 25, 153-169.

World Health Organization (2018). ICD-11 for mortality and morbidity statistics. Retrieved December 8, 2020, from: https://icd.who.int/ browse11/1-m/en\#/http://id.who.int/icd/entity/1630268048.

Young, K. S. (2008). Internet sex addiction: Risk factors, stages of development, and treatment. American Behavioral Scientist, 52, $21-$ 37.

Zapf, J. L., Greiner, J., \& Carroll, J. (2008). Attachment styles and male sex addiction. Sexual Addiction \& Compulsivity, 15, 158-175.

Publisher's Note Springer Nature remains neutral with regard to jurisdictional claims in published maps and institutional affiliations. 